\title{
Semiconductor Photocatalyst of Tin Oxide Quantum Dots Prepared in Aqueous Solution for Degradation of Organic Pollutants in Contaminated Water
}

\author{
Jianqiao LIU, Ye HONG, Xinyue TIAN, Xiangxu MENG, Ge GAO, Tiantian HE, \\ Yichen NIE, Guohua JIN, Zhaoxia ZHAI, Ce FU*
}

College of Information Science and Technology, Dalian Maritime University, Dalian 116026, Liaoning, China P.R. crossref http://dx.doi.org/10.5755/j02.ms.25558

Received 25 March 2020; accepted 17 June 2020

\begin{abstract}
Stannous chloride and thiourea are used as source materials to prepare $\mathrm{SnO}_{2}$ quantum dots in the aqueous solution by a facile hydrolysis-oxidation process. The quantum dots have an average size of $1.9 \mathrm{~nm}$ with good dispersibility as well as long-term stability, and are validated to be an effective photocatalyst for the degradation of organic oil pollutants in contaminated water. The pollutant is removed by the quantum dots exposed to ultraviolet-visible irradiation at room temperature. The optimized condition is concluded to be a solution with quantum dot concentration of $10^{-3} \mathrm{~mol} / \mathrm{L}$ and the degradation speed reaches the maximum at the 12 th hour after irradiation. After 48 hours, $91.9 \%$ of octane is removed, concluding a high degradation efficiency. The prepared $\mathrm{SnO}_{2}$ quantum dots are potentially applicable in the remediation of marine environment as they hold the advantages of high efficiency, low cost and being environmentalfriendly. The promotion and inhibition mechanisms of the photocatalytic $\mathrm{SnO}_{2}$ QDs at low and high concentrations are discussed.
\end{abstract}

Keywords: tin oxide, quantum dot, photocatalyst, pollution remediation, water environment.

\section{INTRODUCTION}

Recent statistics reported that there were about 3 oil spill incidents beyond 50 tons in China and 1049 tons of oil were lost to seawater annually [1]. The oil content of the seawater in the most of coastal areas had exceeded the water quality criteria (WQC) by 10-100 times [2]. Several conventional methods had been developed to remove the oil waste in the contaminated water but they were slow in processing, difficult in operation, low in removal efficiency and expensive in price [3-5]. Therefore, it is of great practical significance to degrade marine organic oil pollution by developing a novel method, which is of low cost, high degradation efficiency, safety and being environment-friendly.

The quantum dot (QD) is a kind of semiconductor with dimensions of several nanometers. It is highly chemicalactive due to the large specific surface area and insufficient coordination atoms on surface, which has a large percentage of suspended bonds. When excited by external irradiation with sufficient energy, the valence electrons are provided possibility to transit to conduction band, forming electron-hole pairs. The excited electrons are able to interact with the adsorbates on the surface of QDs. When the adsorbates are organic pollutants, such as fuel oil, diesel or other petrochemical products, they will be oxidized to carbon dioxide and water by the electrons in the conduction band. In this process, the degradation of organic pollutants is completed with the assistance of QD photocatalysts [6-9]. There are a dozen types of semiconductor QD, such as $\mathrm{ZnS}, \mathrm{CdS}, \mathrm{WO}_{3}, \mathrm{MoS}_{2}$ as well as $\mathrm{TiO}_{2}$-based nanomaterials [10-16] and among them $\mathrm{TiO}_{2}$ is the most popular photocatalyst [17]. However, its

\footnotetext{
* Corresponding author. Tel.: +86-411-84729934; fax: +86-41184729934. E-mail address: fu_ce@dlmu.edu.cn (C. Fu)
}

photocatalytic activity is suppressed by the high compensation rate of electron-hole pairs. Meanwhile, tin oxide $\left(\mathrm{SnO}_{2}\right)$ is another semiconductor photocatalyst candidate that has the characteristics of good stability, lowcost and simple preparation [18-20]. Furthermore, it is free of toxic elements and has good compatibility with the natural environment. Thus, it has the unique advantage to be applicable in oil pollution degradation and environment remediation.

In the present work, $\mathrm{SnO}_{2}$ QDs are prepared in aqueous solution with $\mathrm{SnCl}_{2} \cdot 2 \mathrm{H}_{2} \mathrm{O}$ as the raw material and $\mathrm{CH}_{4} \mathrm{~N}_{2} \mathrm{~S}$ as the catalyst. The photocatalytic performance of $\mathrm{SnO}_{2}$ QDs is investigated by the degradation of octane in the contaminated water. An effective method is obtained to remove organic pollutants for environment remediation. The influences of QD concentration and irradiation time on photocatalytic properties are concluded. The mechanism of semiconductor QD photocatalyst is also discussed.

\section{EXPERIMENTAL DETAILS}

$\mathrm{SnO}_{2}$ QDs were prepared from the analytical source reagents of $\mathrm{SnCl}_{2} \cdot 2 \mathrm{H}_{2} \mathrm{O}$ and $\mathrm{CH}_{4} \mathrm{~N}_{2} \mathrm{~S}$ by a facile method, which had been described before $[21,22] . \mathrm{SnCl}_{2} \cdot 2 \mathrm{H}_{2} \mathrm{O}$ and $\mathrm{CH}_{4} \mathrm{~N}_{2} \mathrm{~S}$ were mixed with mole ratio of $10: 1$ by dissolving into deionized water. The mixture was stirred in a magnetic stirring apparatus for 24 hours at room temperature. The QD concentration in aqueous solution was indicated by the concentration of Sn atoms. The initial QD concentration was kept to be $0.2 \mathrm{~mol} / \mathrm{L}$ and the samples were diluted to $10^{-5}-10^{-1} \mathrm{~mol} / \mathrm{L}$ for further operations.

The crystal structure of $\mathrm{SnO}_{2}$ QDs was analyzed by Xray diffraction (XRD, D/MAX-Ultima, Rigaku, Tokyo, Japan). The morphology was observed by high resolution transmission electron microscopy (HRTEM, JEM-3200FS, 
JEOL, Tokyo, Japan) and atomic force microscopy (AFM, Bruker Dimension Icon, Bruker, Karlsruhe, Germany). The Zeta potential was obtained by Malvern Zetasizer Nano ZS 90 (Malvern Panalytical Ltd., Malvern).

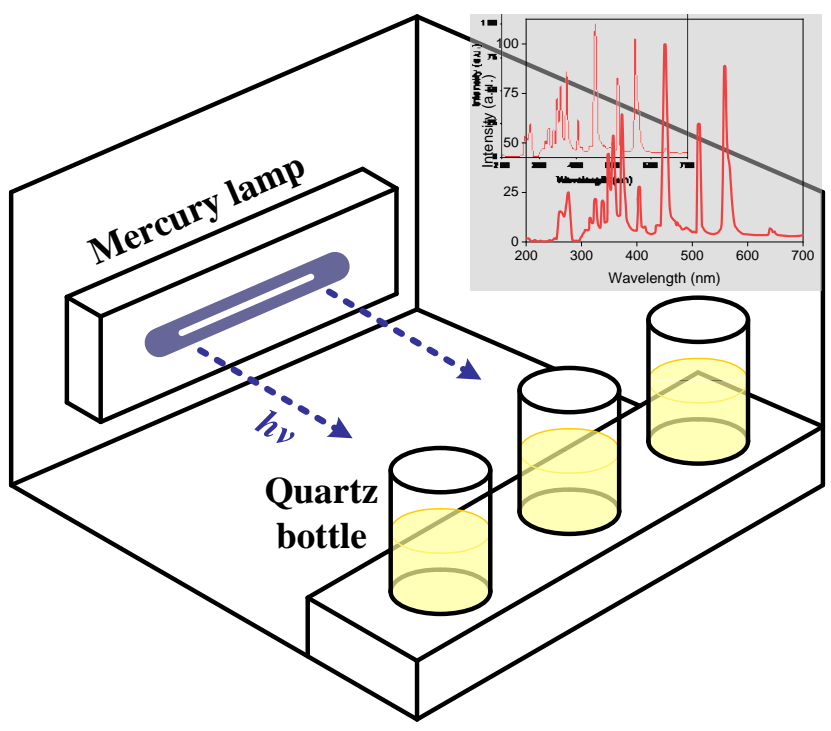

Fig. 1. Schematic drawing of facilities for octane degradation in quartz bottles under the irradiation from a high pressure mercury lamp

The photocatalytic performance of $\mathrm{SnO}_{2}$ QDs was evaluated by the degradation of octane under the irradiation of ultraviolet-visible (UV-Vis) light at room temperature. The schematic drawing of the facilities for octane degradation is illustrated in 0 . A high pressure mercury lamp (LT250, Lantian Development, Hebei, China) was employed to produce the emission of $150 \mathrm{~W}$, the spectrum of which was shown in 0 inset. Octane $\left(\mathrm{C}_{8} \mathrm{H}_{18}\right)$, which was the main compound in fuel oil, was selected to be the representative of organic pollutants in contaminated water. Octane was weighed and commingled into $30 \mathrm{ml} \mathrm{SnO}_{2}$ QD aqueous solution with a certain QD concentration and the suspension solution was stirred in high-purity quartz bottles for $30 \mathrm{~min}$. Then, the solution was exposed to irradiation for 2-48 hours. After degradation under irradiation, the remaining octane was separated and weighed. The degradation efficiency $(D)$ was defined to be $D=\left(1-m / m_{0}\right) \times 100 \%$, where $m$ and $m_{0}$ were the mass of octane before and after the degradation, respectively.

\section{RESULTS AND DISCUSSION}

0 shows the HRTEM morphology and macroscopical observation of $\mathrm{SnO}_{2}$ QDs in the aqueous solution. The aqueous solution appears to be transparent in yellow and can be maintained stable for month because of the Zeta potential of $17 \mathrm{mV}$. The QDs have an average grain size of $1.9 \mathrm{~nm}$ with good dispersibility and uniformity, as shown by the size distribution in $0 \mathrm{c}$. Some clear diffraction patterns of crystallite facets can also be observed, showing a good crystallinity of $\mathrm{SnO}_{2}$ QDs. 0 shows the AFM morphology of the $\mathrm{SnO}_{2}$ QD thin film, which is spincoated on a substrate of polished silicon wafer. The morphology of thin film appears to be uniform and most positions have a relative height between -2 to $2 \mathrm{~nm}$. Most of the height differences among neighboring positions are within $\pm 1 \mathrm{~nm}$, illustrating the grain size of $2 \mathrm{~nm}$.
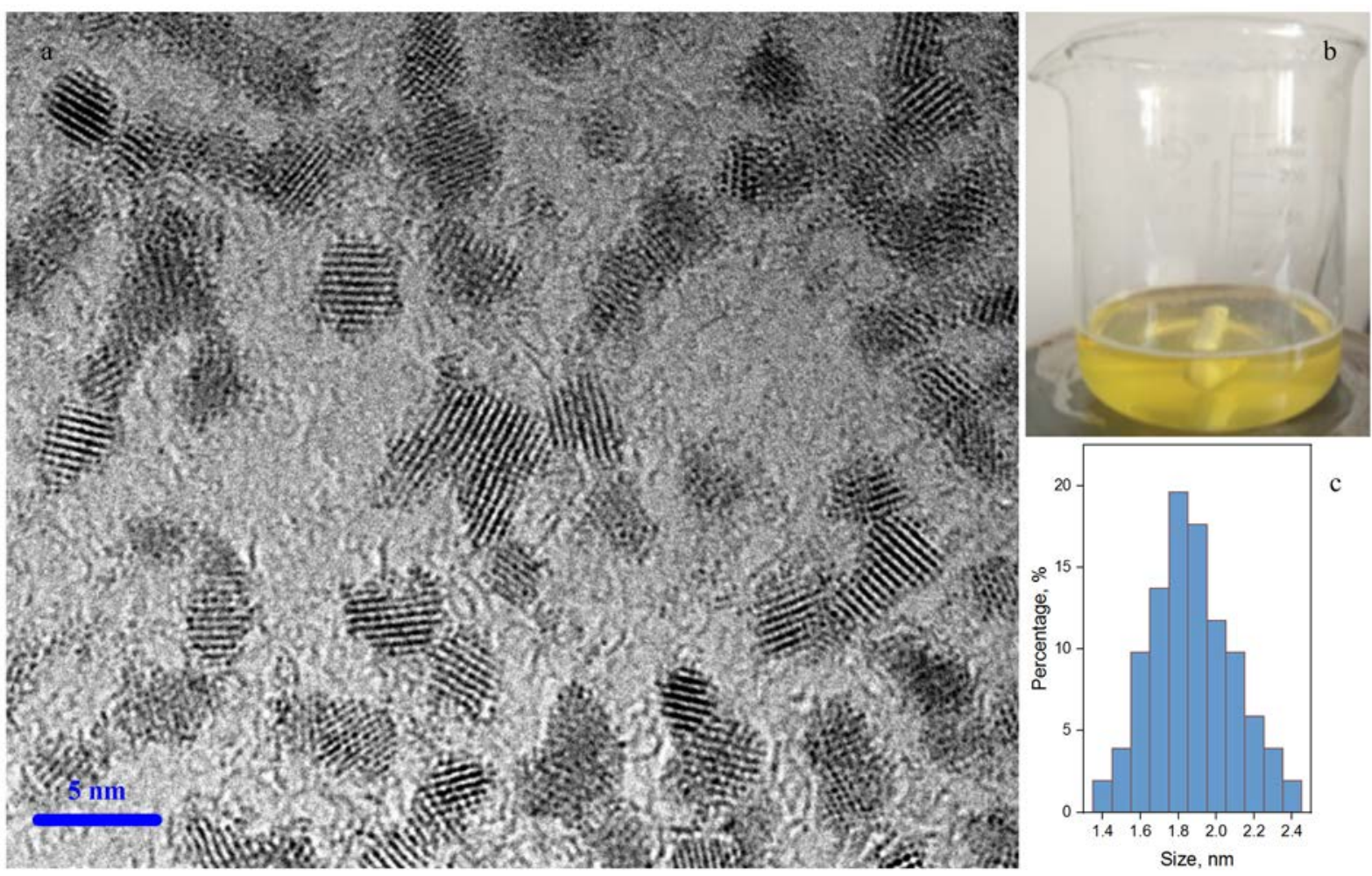

Fig. 2. Morphology of $\mathrm{SnO}_{2}$ quantum dots: a-HRTEM; b-photo; c-size distribution 

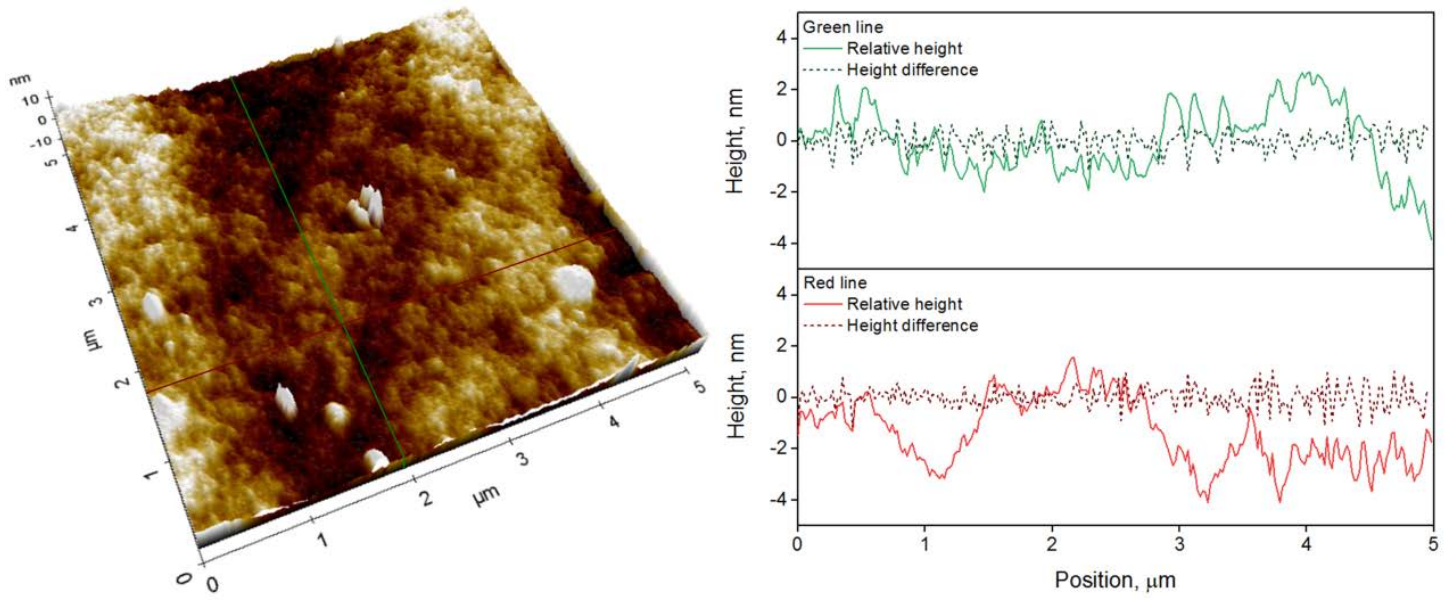

Fig. 3. AFM observation of $\mathrm{SnO}_{2}$ quantum dots spin-coated on a substrate of polished silicon wafer

0 reveals the XRD pattern of $\mathrm{SnO}_{2}$ QDs with standard diffraction peaks [23]. An obvious (211) peak is observed while the (110) and (101) peaks are inapparent. The crystallite size of QDs is calculated to be $2.0 \mathrm{~nm}$ from the (211) peak according to Scherrer's formula and this conclusion is consistent with the results from HRTEM and AFM observations.

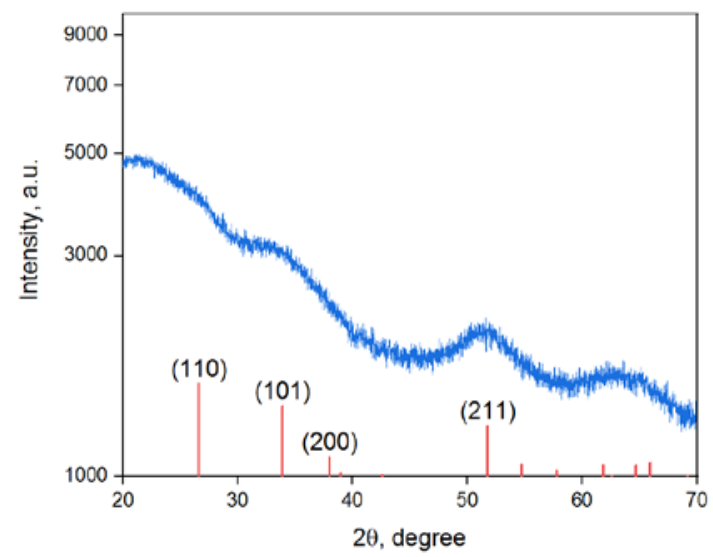

Fig. 4. XRD pattern of $\mathrm{SnO}_{2}$ quantum dots with standard diffraction peaks

0 illustrates the influence of QD concentration on the degradation efficiency of octane. An optimized QD concentration is observed at $10^{-3} \mathrm{~mol} / \mathrm{L}$, which removes $13.8 \%$ of octane in 6 hours. The optimized concentration infers that there are two mechanisms that influence the degradation performance of $\mathrm{SnO}_{2}$ QDs. One of them promotes the degradation under low QD concentration while the other one makes inhibition of octane elimination. In general, the degradation mechanism of QD photocatalyst can be ascribed to the oxidation of organic pollutants by the electrons, which are activated by light irradiation. When the QD concentration is low, the number of photogenerated electrons is so small that the degradation efficiency is quite limited. With the increase of QD concentration, the octane degradation is promoted by the increasing electrons activated from QDs. However, when the QD concentration reaches to a certain level, the possibility of collision between QDs becomes remarkable based on Brownian motions. In this case, there is a selfinhibition effect [24] that the photogenerated electrons on the QD surface are captured by a neighbor grain, which prevents electrons from interacting with octane molecules. Therefore, the photocatalytic process is interrupted and a decreasing degradation efficiency is observed.

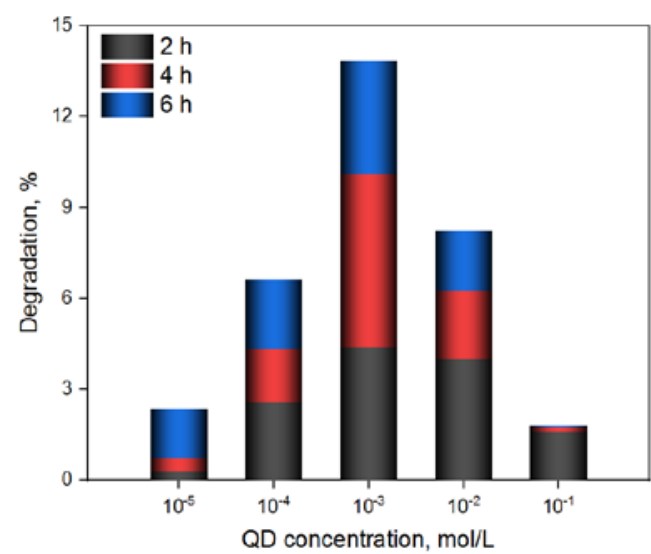

Fig. 5. The influence of QD concentration on degradation of the octane pollutant

Fig. 6 reveals the performance of $\mathrm{SnO}_{2}$ QDs with concentration of $10^{-3} \mathrm{~mol} / \mathrm{L}$ on octane degradation in a period of 48 hours. The degradation speed reaches the maximum of $4.1 \% / \mathrm{h}$ at irradiation time of the 12 th hour. The speed slows down when further octane degradation takes place and approaches to zero at the 48 th hour.

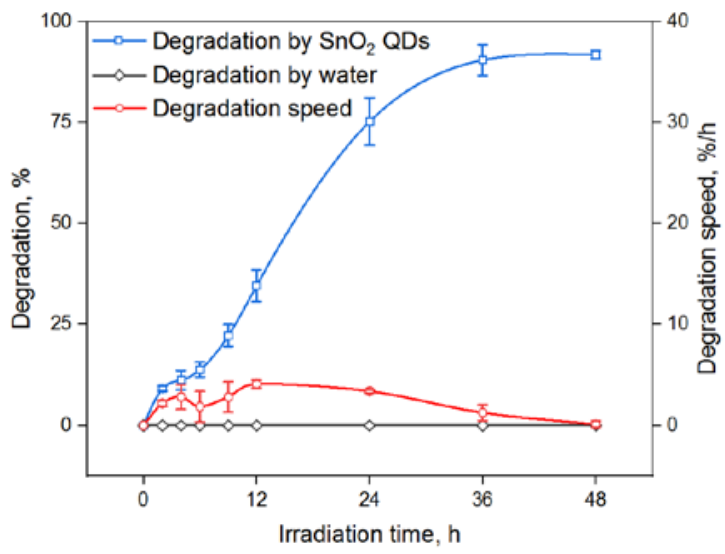

Fig. 6. Octane degradation performance of $\mathrm{SnO}_{2}$ quantum dots with concentration of $10^{-3} \mathrm{~mol} / \mathrm{L}$ and deionized water in a period of 48 hours

At this time, $91.9 \%$ octane is removed by the $\mathrm{SnO}_{2}$ 
QDs under irradiation.Compared to the photocatalytic activity of the popular $\mathrm{TiO}_{2}$-based nanostructures, which degradation efficiency are $87.5 \%$ to quinalphos [25], $91.7 \%$ to 2-chlorophenol [25] as well as $90 \%$ [26] and $97.6 \%$ [15] to Rhodamin B, the present $\mathrm{SnO}_{2}$ QDs show a degradation performance in the high level. However, the degradation efficiency is not only decided by the characteristics of photocatalysts, but also influenced by the properties of target organics. Moreover, the environmental conditions of $\mathrm{pH}$ value, oxygen supply and irradiation power are the key parameters that decide the photocatalytic activity. Nevertheless, the present degradation efficiency of $\mathrm{SnO}_{2}$ QDs shows a bright prospect of the photocatalyst for practical application in water remediation.

\section{CONCLUSIONS}

The $\mathrm{SnO}_{2}$ QDs are prepared in the aqueous solution via a facile hydrolysis-oxidation process. The average size of QDs is concluded to be $1.9 \mathrm{~nm}$ and a Zeta potential of $17 \mathrm{mV}$ guarantees a good dispersibility as well as longterm stability in the aqueous solution. The photocatalytic performance of QDs is validated by the degradation of octane in water under irradiation at room temperature. A high degradation efficiency of $91.9 \%$ is obtained after 48 hour irradiation. The QDs with concentration of $10^{-3}$ $\mathrm{mol} / \mathrm{L}$ shows the maximum degradation efficiency and the degradation speed reaches the peak at the 12 th hour. Two mechanisms are discussed in the removal of octane pollutant. One of them promotes the degradation at low QD concentration and the other one leads to inhibition of photocatalytic performance at high QD concentration because of the self-inhibition between $\mathrm{SnO}_{2}$ QDs.

\section{Acknowledgments}

This work is financially supported by the National Natural Science Foundation of China (Grant No. 11704055), the Liaoning Natural Science Foundation (Grant No. 20180510021, the Joint Research Fund Liaoning-Shenyang National Laboratory for Materials Science), the Dalian High-level Talents Innovation Supporting Program (Grant No. 2017RQ073), the Fundamental Research Funds for the Central Universities (Grant No. 3132019348 and 3132020209) and the Large Instruments and Facilities Shared Foundation of Dalian Maritime University.

\section{REFERENCES}

1. Xiong, S., Long, H., Tang, G., Wan, J., Li, H. The Management in Response to Marine Oil Spill from Ships in China: A Systematic Review Marine Pollution Bulletin 96 (1) 2015: pp. 7-17. https://doi.org/10.1016/j.marpolbul.2015.05.027

2. Yan, Z., Pan, J., Gao, F., An, Z., Liu, H., Huang, Y., Wang, $\mathbf{X}$. Seawater Quality Criteria Derivation and Ecological Risk Assessment for Oil Pollution in China Marine Pollution Bulletin 142 2019: pp. 25-30. https://doi.org/10.1016/j.marpolbul.2019.02.033

3. Swedmark, M., Granmo, A., Kollberg, S. Effects of Oil Dispersants and Oil Emulsions on Marine Animals Water Research 7 (11) 1973: pp. 1649-1672. https://doi.org/10.1016/j.apor.2008.07.001
4. Muttin, F. Structural Analysis of Oil-Spill Containment Booms in Coastal and Estuary Waters Applied Ocean Research 30 (2) 2008: pp. 107-112. https://doi.org/10.1038/nature06484

5. Jones, D.M., Head, I.M., Gray, N.D., $\quad$ Adams, J.J., Rowan, A.K., Aitken, C.M., Bennett, B., Huang, H., Brown, A.M., Bowler, B.F.J. Crude-Oil Biodegradation Via Methanogenesis in Subsurface Petroleum Reservoirs Nature 451 (7175) 2008: pp. 176-180. https://doi.org/10.1007/s10853-010-5113-0

6. Hanaor, D., Sorrell, C.C. Review of the Anatase to Rutile Phase Transformation Journal of Materials Science 46 (4) 2011: pp. 855-874. https://doi.org/10.1007/s10853-010-5113-0

7. Pelaez, M., Nolan, N.T., Pillai, S.C., Seery, M.K., Falaras, P., Kontos, A.G., $\quad$ Dunlop, P.S.M., Hamilton, J.W.J., Byrne, J.A., Oshea, K.E. A Review on the Visible Light Active Titanium Dioxide Photocatalysts for Environmental Applications Applied Catalysis Benvironmental 125 2012: pp. 331-349. https://doi.org/10.1016/j.apcatb.2012.05.036

8. Shaham-Waldmann, N., Paz, Y. Away from $\mathrm{TiO}_{2}$ : A Critical Minireview on the Developing of New Photocatalysts for Degradation of Contaminants in Water Materials Science in Semiconductor Processing 42 2016: pp. $72-80$. https://doi.org/10.1016/j.mssp.2015.06.068

9. Banerjee, S., Dionysiou, D.D., Pillai, S.C. Self-Cleaning Applications of $\mathrm{TiO}_{2}$ by Photo-Induced Hydrophilicity and Photocatalysis Applied Catalysis B: Environmental 176-177 2015: pp. 396-428.

https://doi.org/10.1016/j.apcatb.2015.03.058

10. Wang, L., Wang, P., Huang, B., Ma, X., Wang, G., Dai, Y., Zhang, X., Qin, X. Synthesis of Mn-Doped Zns Microspheres with Enhanced Visible Light Photocatalytic Activity Applied Surface Science 391 2017: pp. $557-564$. https://doi.org/10.1016/j.apsusc.2016.06.159

11. Jin, J., Yu, J., Guo, D., Cui, C., Ho, W. A Hierarchical ZScheme CdS- $\mathrm{WO}_{3}$ Photocatalyst with Enhanced $\mathrm{CO}_{2}$ Reduction Activity Small 11 (39) 2015: pp. 5262-5271. https://doi.org/10.1002/smll.201500926

12. Li, Y., Li, Y., Araujo, C.M., Luo, W., Ahuja, R. SingleLayer $\mathrm{MoS}_{2}$ as an Efficient Photocatalyst Catalysis Science \& Technology 3 (9) 2013: pp. 2214-2220. https://doi.org/10.1039/c3cy00207a

13. Li, G., Zhang, D., Yu, J. A New Visible-Light Photocatalyst: CdS Quantum Dots Embedded Mesoporous $\mathrm{TiO}_{2}$ Environmental Science \& Technology 43 (18) 2009: pp. $7079-7085$. https://doi.org/10.1021/es9011993

14. Maeda, K., Takata, T., Hara, M., Saito, N., Inoue, Y., Kobayashi, H., Domen, K. GaN:ZnO Solid Solution as a Photocatalyst for Visible-Light-Driven Overall Water Splitting Journal of the American Chemical Society 127 (23) 2005: pp. 8286-8287. https://doi.org/10.1021/ja0518777

15. Zeng, T., Shi, D., Cheng, Q., Liao, G., Zhou, H., Pan, Z. Construction of Novel Phosphonate-Based $\mathrm{MOF} / \mathrm{P}-\mathrm{TiO}_{2}$ Heterojunction Photocatalysts: Enhanced Photocatalytic Performance and Mechanistic Insight Environmental Science: Nano 7 (3) 2020: pp. 861-879. https://doi.org/10.1039/C9EN01180C

16. Wang, R., Tang, T., Lu, G., Huang, K., Feng, S., Zhang, X., $\quad$ Tao, X., $\quad$ Yin, H., $\quad$ Lin, Z., $\quad$ Dang, Z. 
Photocatalytic Degradation of Polybrominated Biphenyls (Pbbs) on Metal Doped Tio2 Nanocomposites in Aqueous Environments: Mechanisms and Solution Effects Environmental Science: Nano 6 (4) 2019: pp. $1111-1120$.

https://doi.org/10.1039/C8EN01309H

17. Weon, S., He, F., Choi, W. Status and Challenges in Photocatalytic Nanotechnology for Cleaning Air Polluted with Volatile Organic Compounds: Visible Light Utilization and Catalyst Deactivation Environmental Science: Nano 6 (11) 2019: pp. 3185-3214. https://doi.org/10.1039/C9EN00891H

18. Liu, J., Lu, Y., Cui, X., Geng, Y., Jin, G., Zhai, Z. GasSensing Properties and Sensitivity Promoting Mechanism of $\mathrm{Cu}$-Added $\mathrm{SnO}_{2}$ Thin Films Deposited by Ultrasonic Spray Pyrolysis Sensors and Actuators B: Chemical 248 2017: pp. $862-867$. https://doi.org/10.3390/s17081852

19. Liu, J., Gao, Y., Wu, X., Jin, G., Zhai, Z., Liu, H. Inhomogeneous Oxygen Vacancy Distribution in Semiconductor Gas Sensors: Formation, Migration and Determination on Gas Sensing Characteristics Sensors 17 (8) 2017: pp. 1852 https://doi.org/10.3390/s17081852

20. Liu, J., Liu, X., Zhai, Z., Jin, G., Jiang, Q., Zhao, Y., Luo, C., Quan, L. Evaluation of Depletion Layer Width and Gas-Sensing Properties of Antimony-Doped Tin Oxide Thin Film Sensors Sensors and Actuators B: Chemical 220 (15) 2015: pp. $1354-1360$. https://doi.org/10.1016/j.snb.2015.07.065

21. Liu, J., Zhang, Q., Xue, W., Zhang, H., Bai, Y., Wu, L., Zhai, Z., Jin, G. Fluorescence Characteristics of Aqueous Synthesized Tin Oxide Quantum Dots for the Detection of
Heavy Metal Ions in Contaminated Water Nanomaterials 9 (9) 2019: pp. 1294.

https://doi.org/10.3390/nano9091294

22. Liu, J., Xue, W., Jin, G., Zhai, Z., Lv, J., Hong, W., Chen, Y. Preparation of Tin Oxide Quantum Dots in Aqueous Solution and Applications in Semiconductor Gas Sensors Nanomaterials 9 (2) 2019: pp. 240 https://doi.org/10.3390/nano9020240

23. Seki, H., Ishisawa, N., Mizutani, N., Kato, M. High Temperature Structures of the Rutile-Type Oxides, $\mathrm{TiO}_{2}$ and $\mathrm{SnO}_{2}$ Journal of the Ceramic Association Japan 92 1984: pp. 219-223. https://doi.org/10.2109/jcersj1950.92.1064_219

24. Zhai, D., Xu, W., Zhang, L., Chang, Y.T. The Role of "Disaggregation" in Optical Probe Development Chemical Society Reviews 43 (8) 2014: pp. 2402-2411. https://doi.org/10.1039/C3CS60368G

25. Sharotri, N., Sharma, D., Sud, D. Experimental and Theoretical Investigations of Mn-N-Co-Doped $\mathrm{TiO}_{2}$ Photocatalyst for Visible Light Induced Degradation of Organic Pollutants s Journal of Materials Research and Technology 8 (5) 2019: pp. 3995-4009. https://doi.org/10.1016/j.jmrt.2019.07.008

26. Abdi, J., Yahyanezhad, M., Sakhaie, S., Vossoughi, M., Alemzadeh, I. Synthesis of Porous $\mathrm{TiO}_{2} / \mathrm{ZrO}_{2}$ Photocatalyst Derived from Zirconium Metal Organic Framework for Degradation of Organic Pollutants under Visible Light Irradiation Journal of Environmental Chemical Engineering 7 (3) 2019: pp. 103096. https://doi.org/10.1016/j.jece.2019.103096

(C) Fu et al. 2022 Open Access This article is distributed under the terms of the Creative Commons Attribution 4.0 International License (http://creativecommons.org/licenses/by/4.0/), which permits unrestricted use, distribution, and reproduction in any medium provided you give appropriate credit to the original author(s) and the source, provide a link to the Creative Commons license, and indicate if changes were made. 